Research Article

\title{
Moisture Migration and Control of New Embankment for Reconstruction and Expansion Project in Southern China
}

\author{
Junhui Zhang, ${ }^{1}$ Feng Li, ${ }^{1}$ Ling Zeng $\mathbb{D}^{2},{ }^{2}$ Junhui Peng, ${ }^{1}$ Le Ding, ${ }^{1}$ and Liang He ${ }^{1,3}$ \\ ${ }^{1}$ National Engineering Laboratory of Highway Maintenance Technology, Changsha University of Science and Technology, \\ Changsha, China \\ ${ }^{2}$ School of Civil Engineering, Changsha University of Science and Technology, Changsha, China \\ ${ }^{3}$ School of Civil Engineering, Chongqing Jiaotong University, Chongqing, China \\ Correspondence should be addressed to Ling Zeng; zl001@csust.edu.cn
}

Received 25 February 2020; Revised 8 May 2020; Accepted 22 May 2020; Published 21 July 2020

Academic Editor: Chunshun Zhang

Copyright (c) 2020 Junhui Zhang et al. This is an open access article distributed under the Creative Commons Attribution License, which permits unrestricted use, distribution, and reproduction in any medium, provided the original work is properly cited.

\begin{abstract}
In hot and humid regions of southern China, the volumetric moisture content of the embankment after opening to traffic for a period of time reaches a stable state, and it is higher than the design value. When it was widened, the humidity gradient and exchange were formed due to the difference in moisture content between the existing and new embankment. To reveal the moisture migration of the existing and new embankment and control the rise of volumetric moisture content in new embankment, six frequency domain reflectometry sensors were installed in existing and new embankment to monitor the volumetric moisture content. A finite element model for the embankment was established and verified with the measured data. And seven numerical analyses of transient seepage in the new embankment of the cushion, cover, and partition using capillary barrier by sand were simulated. The results show that the volumetric moisture contents of the new embankment in southern China gradually increase and eventually reach an equilibrium state. The increase in water comes from the slope, the foundation, and the existing embankment. Early in the first 1 2 years, the water mainly comes from the foundation and the existing embankment. After that, as time goes by, the water comes mostly from the slope infiltration and gradually migrates to the foundation and the existing embankment. Finally, the volumetric moisture content and the water storage gradually reach equilibrium. The volumetric moisture content of the new embankment using capillary barrier by sand at the cushion, the cover, and the partition is maintained as the construction volumetric moisture content. This combination is a very effective method to control the humidity stability of the new embankment in southern China.
\end{abstract}

\section{Introduction}

In the field construction, the embankment soil is generally compacted by the optimum moisture content (OMC) within $2 \%$ error $[1,2]$. Due to the hot and humid environment in southern China, the moisture migration between embankment and surrounding atmosphere will appear sharply [3-5]. And then, the moisture of embankment will increase gradually from the OMC and finally reach an equilibrium state. This equilibrium state depends on the surrounding climate, soil properties, and so on. Yao et al. [6] found that the equilibrium moisture content of the embankment in southern China will increase to 1.2 times of OMC. Many expressways need to be widened since the existing expressways cannot meet the demands of the growing traffic during the operation for many years [7]. When these embankments were widened, the new embankment was also compacted by the OMC. Then, the moisture will migrate between the existing and new embankment owing to their moisture content difference. This is helpful to a series of performance deteriorations of the new embankment, such as a loss of the structural bearing capacity $[8,9]$, an increase of lateral pressure [10], a reduction of the resilient modulus $[11,12]$, and an increase of permanent deformation $[13,14]$. Therefore, it is extremely important to reveal the moisture migration process between the existing and new embankment. And then, some measures for the new embankment can be put forward to control the humidity stability. 
Many researchers have conducted studies on the moisture migration between the embankment and the surrounding environment $[13,15,16]$. Jie et al. [17] studied the subgrade moisture variations through laboratory model experiment and numerical simulation. An et al. [18] conducted on-site monitoring and numerical analysis of an embankment in France. Their results indicated that the influence depth of soil-atmosphere interaction is limited for volumetric moisture content, but it was much greater for temperature. Lees et al. [19] analyzed moisture data from four monitored sections of the downstream slope at Aldenham embankment dam for 10 years. The measured moisture contents were generally about half the liquid limit values. Tao et al. [20] subjected a set of laboratory-scale soil slopes to instability, through three different modes of raising water level. The results of model tests showed that the volumetric moisture content of the slope region where the localized failure initiated was noted reaches a nearly saturated value. Wang et al. [21] investigated the soil-atmosphere interaction for foundation by numerical analysis using data from Nairobi. It was further noted that the migration of moisture and the vertical movement within the foundation are obviously affected by rainfall and evapotranspiration. Hatami et al. [22] investigated the seasonal change of the humidity field of embankments. Yao et al. [23] found that the volumetric moisture content of the new embankment increases significantly through FDR sensors and simulation. However, they only thought that the increase in the humidity of the new embankment was due to the moisture migration between the embankment and the surrounding atmosphere. And the moisture migration between the existing and new embankment was not considered. In the paper of Yao et al., the initial water content of the old embankment in the simulation was the construction moisture content rather than the equilibrium moisture content, which is inconsistent with the actual situation. In addition, only the phenomenon of the increasing moisture content in the new embankment had been revealed, but the cause of this phenomenon had not been analyzed in detail.

In order to block water from entering slopes, earth-rock dams, and embankments, countless researchers have provided a series of measures, as sand or stone cushion, clay cover, geomembrane, etc. Among them, the capillary barrier is widely used. The capillary barrier was formed by the contrast in the pore sizes of fine-grained soil (e.g., clay) and coarse-grained soil (e.g., sand or stone) forms, which can impede the downward moisture migration into the coarse soils. Because of the different soil-water characteristic curves and permeability functions due to the difference in the particle sizes of the two soils, it limited the rainfall penetration into the soil. Before the suction at the interface reached the breakthrough suction value, the water hardly penetrated into the coarse soil layer. The capillary barrier has been studied by Nicholson et al. [24], Gee et al. [25]. Nirjhar et al. [26] found that the height of the capillary rise of sand and loamy sand was $50 \mathrm{~cm}$ and $70 \mathrm{~cm}$, respectively. Cao et al. [27] found that several breakthroughs occurred each year in a capillary barrier system because, during rainfall, the suction at the interface between the fine-texture soil and its underlying coarse soil will decrease to a value that permits water to enter and form a continuous network. The on-site assessment of the effectiveness of the capillary barrier showed that the flow quantity at the toe of the capillary barrier was lower than the maximum seepage rate required by the strictest landfill regulations [28]. In Singapore, a field experiment showed that a capillary barrier has the effect of reducing rainfall infiltration on slope [29]. The rainwater is stored temporarily in the fine-texture soil and discharged after evapotranspiration and lateral drainage. The capillary barrier is considered effective when the combined amount of evapotranspiration, lateral diversion, and water storage capacity is significantly higher than the amount of rainfall infiltration [30]. Infiltration tests on soil columns of finer layers over coarser layers were conducted to investigate the capillary barrier [31, 32]. Even though numerous studies have shown that the capillary barrier had a good effect, to the authors' knowledge, no numerical investigation in two dimensions has been conducted to study which combination method achieves the purpose of blocking the water migration of the new embankment.

Thus, the objectives of this paper are to reveal the moisture migration between the existing and new embankment and propose methods controlling humidity stability of the new embankment. This study was organized as follows. First, in the existing and new embankment of the Chang-Zhang expressway located in southern China, six frequency domain reflectometry (FDR) sensors were embedded to monitor the volumetric moisture content. Then, a finite element model of this embankment was built, and input parameters including the meteorological data, hydraulic and thermal properties of existing and new embankment soils were determined and the simulations and measured data were compared. After that, the changes of volumetric moisture content, flow, and volumetric water storage of the new embankment were revealed, and the influences of 7 combinations of the new embankment using capillary barrier by sand were investigated. Finally, the influence of resilient modulus and slope stability using the capillary barrier was analyzed.

\section{Field Moisture Monitoring of the Existing and New Embankment}

The K64 + 700 with a widening of $7.5 \mathrm{~m}$ commenced in 2013/ 7 on the Chang-Zhang expressway reconstruction and extension project in Jiangxi Province, southern China, was selected, as shown in Figure 1. This place has a subtropical monsoon climate, with an average annual temperature of $16.3 \sim 19.5^{\circ} \mathrm{C}$ and annual precipitation of $1341 \sim 1943 \mathrm{~mm}$. The existing expressway, opened to traffic in 1997/7, was a $27 \mathrm{~m}$ wide, a bidirectional, four-lane expressway with an asphalt concrete pavement. After a period of over a decade of operation, it was found that the volumetric moisture content of the existing embankment soil is higher than the initial volumetric moisture content of the original construction.

For the reconstruction and expansion project of the Chang-Zhang expressway, six frequency domain reflectometry (FDR) sensors to estimate the volumetric moisture 


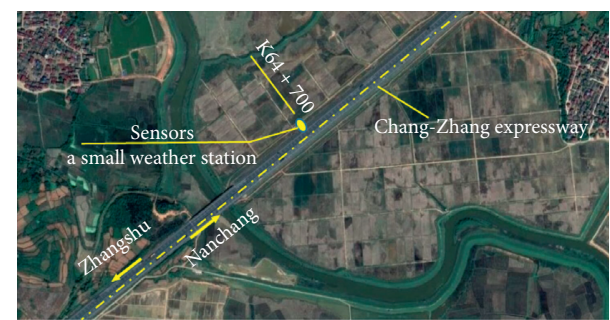

FIGURE 1: Field measurement zone.

content of soil by measuring the apparent dielectric constant according to the electromagnetic wave propagation were buried in the existing and new embankment, as shown in Figure 2(a). FDR is a voltage sensor with $12 \mathrm{~V}$ input, $0 \sim 2.5 \mathrm{~V}$ output, $0 \sim 100 \%$ volumetric moisture range and $0.1 \%$ moisture accuracy, $0 \sim 50^{\circ} \mathrm{C}$ temperature range, and $0.5^{\circ} \mathrm{C}$ temperature accuracy. The embedded depth was $4.2 \mathrm{~m}$ down from the top of the embankment during the construction.

In the existing embankment, the installation of the FDR sensors consisted of three steps. First, a horizontal hole was drilled at an embedded depth of the side slope. Then, the FDR sensor was fixed on the top of a PVC pipe with a length of $1 \mathrm{~m}$ and a diameter of $50 \mathrm{~mm}$. Finally, the FDR sensor was completely inserted into the soil by pushing the other end of the PVC tube to reach the bottom of the horizontal hole. Similarly, in the new embankment, the installation of the FDR sensors was also divided into three steps. The first step was to manually excavate a cavity with a length of $400 \mathrm{~mm}$, a width of $300 \mathrm{~mm}$, and a depth of $200 \mathrm{~mm}$ by a certain interval at the preset elevation of the embankment and then compact and level the embankment surface. The second step was to insert the FDR sensor tightly into the soil at the bottom of the cavity in the transverse direction of the embankment. Finally, a small groove with a width of $100 \mathrm{~mm}$ and a depth of $200 \mathrm{~mm}$ was excavated along the transverse direction to lead the sensor wires to the outer side of the new embankment slope. During the installation of the sensor, we should pay attention to the protection of the probe, and the volumetric moisture content and compaction of the trench backfill soil where the cable is placed were consistent with those before the excavation.

Simultaneously, to monitor the changes in the volumetric moisture content and the temperature of the air surrounding the embankment and the changes in the volumetric moisture content and temperature of the soil inside the embankment in real-time, a weather station with data acquisition and transmission was installed on the outside of the dirt shoulder, as shown in Figure 2(b). This weather station contained a rain sensor, a temperature sensor, an air humidity sensor, a wind speed, and direction sensor, all mounted on a support bar. And a meter box that enables monitoring of real-time data remotely was fixed beside the support bar, which included the data acquisition module for FDR sensors, the data acquisition module for meteorological parameters, the wireless transmission module, and a power storage system. In the monitoring period, the data were recorded from 2013/7 to 2017/1, and the sampling frequency of the soil volumetric moisture content was once a day.
Figure 3 shows the variation of the volume moisture contents of the embankment soil. It is observed that the volumetric moisture contents measured by the FDR sensors \#4 and \#6 (which are close to the outer side of the embankment slope) show a more significant change in amplitude than the values measured by sensors \#3-\#5 (which are installed in the soil masses of the existing and new embankment). This is because, at the locations of the former three sensors (\#4, \#5, and \#6), the soil is more significantly affected by meteorological factors (e.g., rainfall, wind speed, and evaporation) than that at the locations of the other sensors. The soil in the new embankment is compacted better with more even compactness (or dry density) and is insignificantly affected by meteorological factors. Under this circumstance, the volumetric moisture contents measured by sensors \# 1 to \#3 show a slightly rising tendency with time. Nevertheless, the results measured by sensor \#6 in the existing embankment show a slightly decreasing tendency with time. This is because when the embankment is widened, the volumetric moisture content in the existing embankment is higher than that in the new embankment, and the moisture migration occurs at the junction of the existing embankment and the new part to some extent.

\section{Numerical Simulations}

To make up for the lack of in situ observation costs and data volume, numerical analyses, combining limited data, in situ conditions with constitutive models, making reasonable assumptions, and performing single-parameter and multiparameter influencing factors research were the most common geotechnical research methods. This study was being performed to investigate the moisture migration of the new embankment, and the best combination method to keep the volumetric moisture content stability was found. The VADOSE/W module of the Geo-Studio 2007 Software (GEOSLOPE International Ltd., Canada) [23] was used to calculate the water infiltration into two layers of soils with contrasting particle sizes.

3.1. Partial Differential Water and Heat Flow Equations. The governing differential equation for water flow can be expressed as

$$
\begin{aligned}
& \frac{1}{\rho_{w}} \frac{\partial}{\partial x}\left(D_{v} \frac{\partial P_{v}}{\partial x}\right)+\frac{1}{\rho_{w}} \frac{\partial}{\partial y}\left(D_{v} \frac{\partial P_{v}}{\partial y}\right)+\frac{\partial}{\partial x}\left(k_{x} \frac{\partial(\psi+y)}{\partial x}\right) \\
&+\frac{\partial}{\partial y}\left(k_{y} \frac{\partial(\psi+y)}{\partial y}\right)+Q=\lambda \frac{\partial P}{\partial t}
\end{aligned}
$$

where $\rho_{w}\left(\mathrm{~kg} \cdot \mathrm{m}^{-3}\right)$ is the water density; $P_{v}(\mathrm{kPa})$ is the vapor pressure of water in soil; $D_{v}(\mathrm{kPa})$ is the diffusion coefficient of vapor in soil pores; $\psi$ is the matrix suction of the soil; $k_{x}$ $\left(\mathrm{m} \cdot \mathrm{d}^{-1}\right)$ is the hydraulic conductivity in the horizontal direction; $k_{y}\left(\mathrm{~m} \cdot \mathrm{d}^{-1}\right)$ is the hydraulic conductivity in the vertical direction; $y(\mathrm{~m})$ is the elevation head; $P(\mathrm{kPa})$ is the pressure; $Q\left(\mathrm{~m}^{3} \cdot \mathrm{d}^{-1}\right)$ is the boundary water flow; $t(\mathrm{~d})$ is the time. 

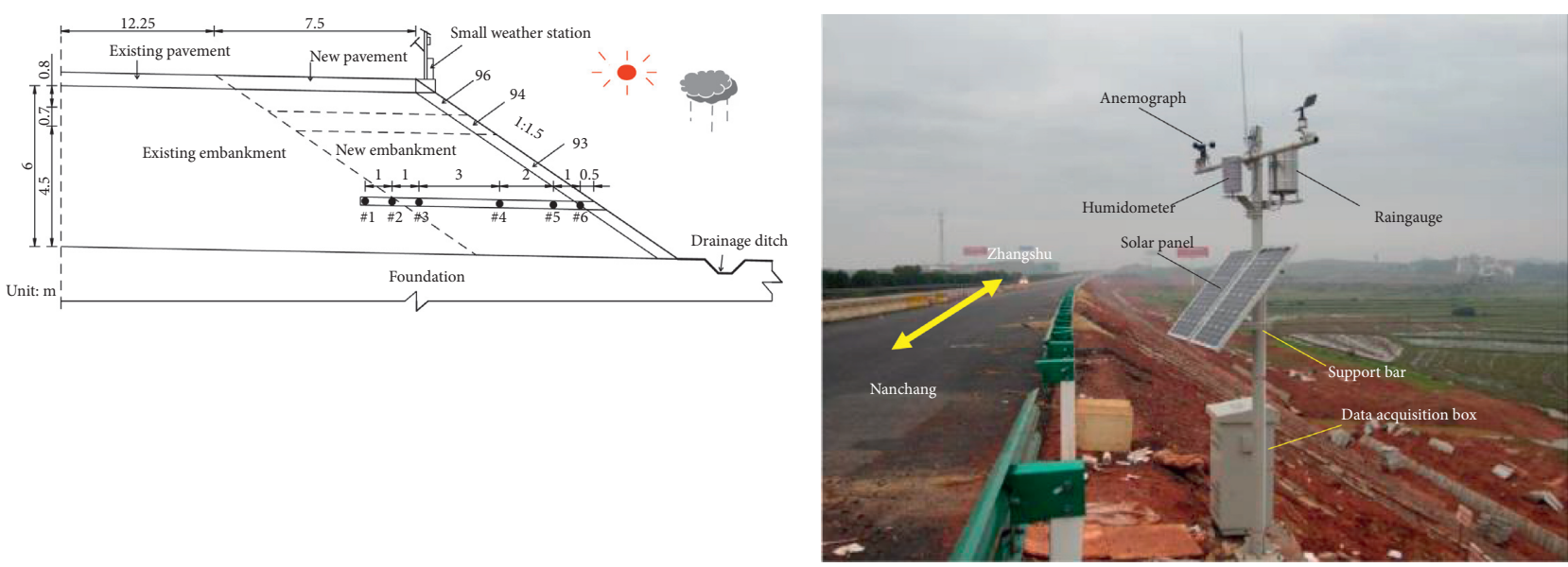

(a)

(b)

FIGURE 2: Field measurement system of the new embankment: (a) installation sketch of the FDR sensors; (b) photograph of the small weather station [23].

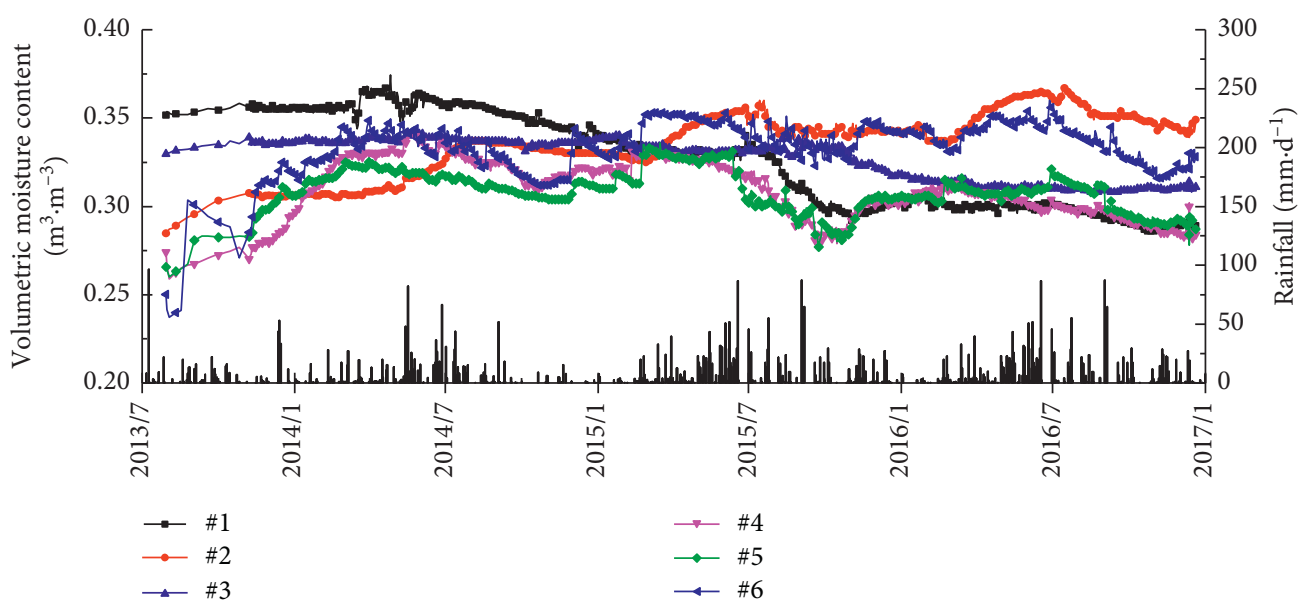

FIGURE 3: Volumetric moisture contents measured by the FDR sensors [23].

The heat transfer equation is

$$
\begin{aligned}
& L_{v} \frac{\partial}{\partial x}\left(D_{v} \frac{\partial P_{v}}{\partial x}\right)+L_{v} \frac{\partial}{\partial y}\left(D_{v} \frac{\partial P_{v}}{\partial y}\right)+\frac{\partial}{\partial x}\left(k_{t x} \frac{\partial T}{\partial x}\right) \\
& \quad+\frac{\partial}{\partial y}\left(k_{t y} \frac{\partial T}{\partial y}\right)+Q_{t}+\rho c V_{x} \frac{\partial T}{\partial x}+\rho c V_{y} \frac{\partial T}{\partial y}=\lambda_{t} \frac{\partial T}{\partial t},
\end{aligned}
$$

where $L_{v}$ is the latent heat of vaporization; $\lambda_{t x}, \lambda_{t y}$ are the thermal conductivities of soil mass in horizontal and vertical directions; $T\left({ }^{\circ} \mathrm{C}\right)$ is the absolute temperature; $Q_{t}$ is the boundary heat flux; $\rho_{c}$ is the volumetric specific heat value; $V_{x}, V_{y}\left(\mathrm{~m} \cdot \mathrm{d}^{-1}\right)$ are the Darcy water velocity in $x$ and $y$ directions.

3.2. Geometrical Model. Only half of the existing and new embankment were simulated because of the symmetry. The geometric model of the embankment was presented in Figure 4 . The width of the top surface with $2 \%$ lateral slope was $19.75 \mathrm{~m}$, of which the existing pavement is $12.75 \mathrm{~m}$, and the new pavement is $7.5 \mathrm{~m}$. The pavement structure was of $0.75 \mathrm{~m}$ thickness and impervious to water. The embankment was $6.5 \mathrm{~m}$ high with a side slope of $1: 1.5$, and the foundation had a depth of $5 \mathrm{~m}$. The drainage ditch had a good drainage performance. The embankment soil was the low-liquid-limit clay with sandy (CLS).

The analysis of mesh sensitivity was performed by assigning different mesh sizes. No significant effect was observed when the mesh size was less than $0.5 \mathrm{~m}$. Thus, with the finite element size of $0.5 \mathrm{~m}$, the numerical model consisted of 1537 elements and 1575 nodes. No water flux and heat flux were considered on the remaining part of the boundaries. The groundwater was $1.8 \mathrm{~m}$ below the natural soil surface, and the soil at the bottom boundary was defined as fully saturated. The water flux boundary and soil heat flux boundary were applied to the surfaces of the Earth shoulder and slope.

The new project is a parallelogram except the top surface being impervious asphalt concrete and the other three faces 


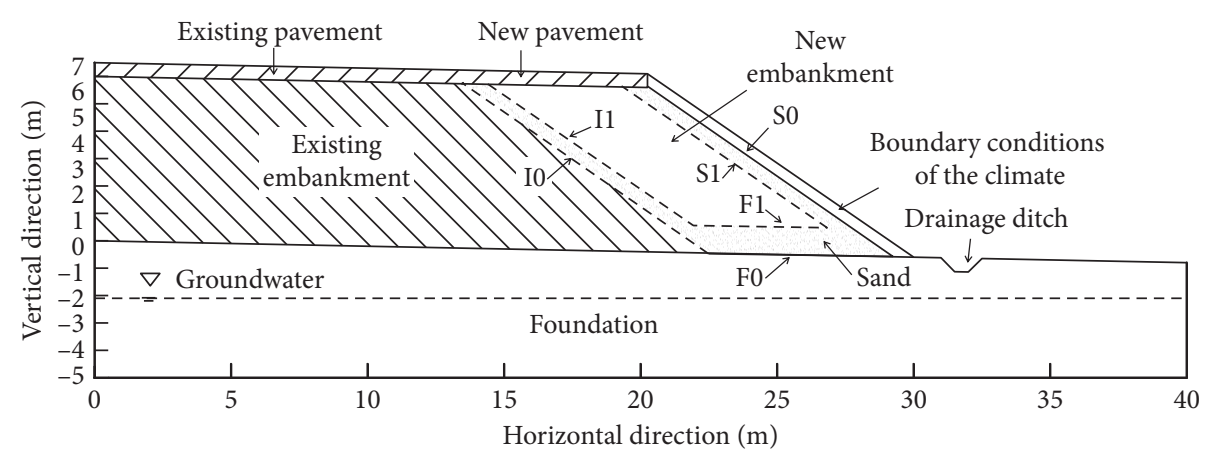

Figure 4: Geometric model of the existing and new embankment.

are the slope $(\mathrm{S})$, the foundation $(\mathrm{F})$, and the interface (I). Two cross-sections (e.g., $\mathrm{S} 0+\mathrm{F} 0+\mathrm{I} 0, \mathrm{~S} 1+\mathrm{F} 1+\mathrm{I} 1$ ) were selected to analyze the volumetric moisture content, flow, and volumetric water storage, as shown in Figure 4. The cross-section $\mathrm{S} 0+\mathrm{F} 0+\mathrm{I} 0$ was composed of the slope below the external vegetation, the foundation face of the embankment and the foundation, and the junction of the existing and new embankment. The cross-section $\mathrm{S} 1+\mathrm{F} 1+\mathrm{I} 1$ was the boundary between the new embankment and the coarse-grained soil using capillary barrier.

3.3. Field Embankment Soil Parameters. In this study, sand as coarse-grained soil and embankment soil as fine-grained soil were composed of a capillary barrier. The physical parameters, hydraulic properties, and thermodynamic properties of the materials for embankment, foundation, and asphalt pavement were gained through laboratory tests and calculations. The soil-water characteristic curves (SWCCs) were measured [23] and the SWCC parameters for these soils are summarized. The SWCCs and permeability curves for these materials are shown in Figure 5. The hydraulic conductivity parameters are shown in Table 1.

3.4. Boundary Conditions. It is well known that the rainwater infiltration and evapotranspiration rate of the embankment depend on several factors such as the rainfall data, temperature, wind speed, soil surface properties, and soil properties. Meteorological parameters were obtained at the small meteorological station, and the parameters for hydraulic and thermal properties of soils could be derived through laboratory tests. A 6-year period was considered from 2013/7 (when the new embankment was built) to 2019/ 7 (when the new embankment was simulated) in southern China. The daily meteorological data collected from the small meteorological station were presented in Figure 6. Initially, the equilibrium moisture content was given to the existing embankment soil, while the optimal moisture content was in the new embankment.

3.5. Combinations of the Capillary Barrier. To reduce or block the impact of groundwater, atmospheric environment, and the existing embankment on the moisture content of the new embankment, there were seven combinations including the cushion (CU), the cover (CO), and the partition (PA) using sand, as summarized in Table 2. Case 1: sand is used as the cover (CO). Case 2: sand is used as the cushion (CU). Case 3: sand is used as the partition (PA). Case 4: sand is used as the cushion and the cover (CU-CO). Case 5: sand is used as the cover and the partition (CO-PA). Case 6: sand is used as the cushion and the partition (CU-PA). Case 7: sand is used as the cushion, the cover, and the partition (CU-COPA).

3.6. Verification of the Numerical Model. In order to further verify the correctness of the numerical simulation, the measured volumetric moisture contents of the FDR sensors and the calculated values through numerical simulations were compared (Figure 7). One can note that the measured data from sensor \#6 close to the outer side of the embankment slope is consistent with the values obtained through numerical calculation and so are their change tendencies. For sensor \#4 embedded in the existing embankment, the measured values are substantially different from and even inconsistent with the ones obtained through numerical calculation. The reason is that the volumetric moisture content of the existing embankment increases when subjected to load. However, the new embankment is filled at an optimum moisture content; thus, the moisture migrates from the existing embankment to the new one, causing a further decline in the volumetric moisture content of the existing embankment. The discrepancy can more effectively reflect the contrast between the measured volumetric moisture contents of the FDR sensors and the calculated values, as shown in Figure 7(b).

\section{Results and Analysis of Existing and New Embankment}

To investigate the moisture migration and the influence of the cushion, the cover, and the partition using the capillary barrier on the predictions of the volumetric moisture content distributions in the new embankment, a series of finite-element transient seepage were carried out.

4.1. Volumetric Moisture Content Contour Variations. Figure 8 shows the variation of the volumetric moisture content (VMC) contours of 0.37 and 0.39 in the existing and 


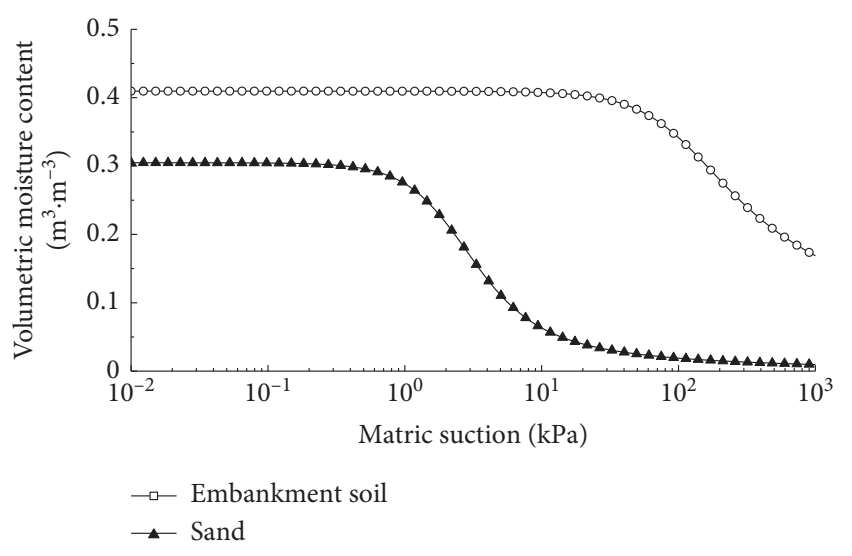

(a)

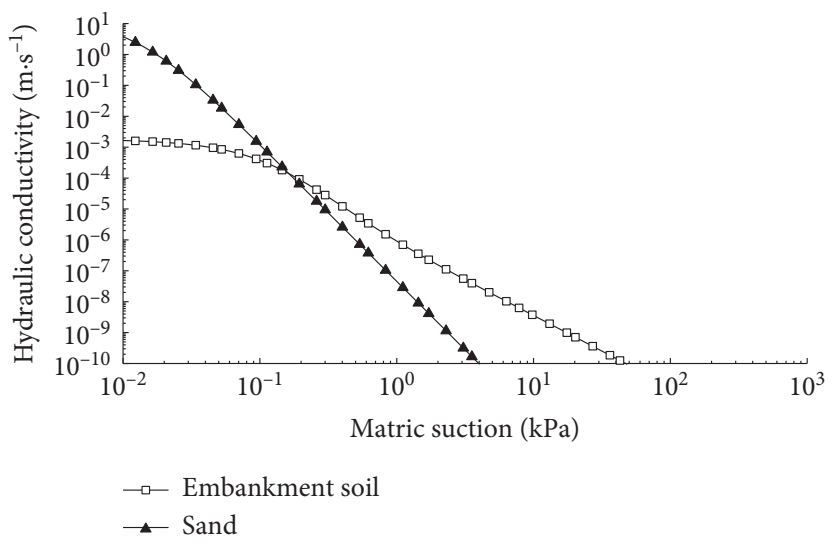

(b)

Figure 5: (a) Soil water characteristic curves and (b) hydraulic conductivity functions of embankment soil and sand.

TABLE 1: Hydraulic and thermal property parameters of embankment soil.

\begin{tabular}{|c|c|c|c|c|c|c|c|}
\hline \multirow[t]{2}{*}{ Materials } & \multirow[t]{2}{*}{$\begin{array}{l}\text { Initial volumetric } \\
\text { moisture content }\end{array}$} & \multirow[t]{2}{*}{$\begin{array}{c}\text { Infiltration } \\
\text { coefficients } K\left(\mathrm{~m} \cdot \mathrm{s}^{-1}\right)\end{array}$} & \multicolumn{3}{|c|}{$\begin{array}{c}\text { Soil water characteristic } \\
\text { curve } \\
\text { of F-X model }\end{array}$} & \multirow[t]{2}{*}{$\begin{array}{c}\text { Thermal } \\
\text { conductivity coefficient }\end{array}$} & \multirow[t]{2}{*}{$\begin{array}{c}\text { Volumetric heat } \\
\text { capacity } J \cdot\left(\mathrm{m}^{-3} \cdot{ }^{\circ} \mathrm{C}^{-1}\right)\end{array}$} \\
\hline & & & $a$ & $n$ & $m$ & & \\
\hline Asphalt pavement & - & $1.0 \times 10^{-14}$ & - & 1.010 & $1.98 \times 10^{6}$ & & \\
\hline Embankment soil & 0.25 & $2.15 \times 10^{-8}$ & 56.24 & 1.8 & 0.55 & 2.354 & $2.85 \times 10^{6}$ \\
\hline Sand & 0.07 & $2.0 \times 10^{-4}$ & 3.02 & 0.82 & 3.2 & 2.897 & $2.49 \times 10^{6}$ \\
\hline Foundation & GWL & $4.75 \times 10^{-6}$ & 72 & 1.62 & 0.48 & 2.742 & $2.76 \times 10^{6}$ \\
\hline
\end{tabular}

new embankment overtime after the expansion. It can be clearly seen that, from $2013 / 7$ to $2014 / 1$, the volumetric moisture content contour in the existing embankment gradually decreased, and the volumetric moisture content contour in the new embankment increased significantly. The scope of influence extends from bottom to top and from outside to inside. From Figure 8(a), in the existing embankment, the contour of 0.37 in the range of $4-6 \mathrm{~m}$ in elevation and $7-12 \mathrm{~m}$ in height is down. Similarly, the contour of 0.39 in the range of $4-6 \mathrm{~m}$ in elevation and $7-12 \mathrm{~m}$ in height is down, as shown in Figure 8(b).

4.2. Volumetric Moisture Content Variations. In Figure 8(b), nine points with the volumetric moisture content measurements are divided into three groups: near top surface points (points A1 and A3), near interface points of the new embankment (points B1 and B3), near interface points of the existing embankment (points C1 and C3). In Figure 9(a), the calculated volumetric moisture contents of three points, A1 to A3, show large variations under the effects of infiltration/ evaporation of soil-atmosphere interfaces. For instance, at point $\mathrm{A} 1$, the calculated volumetric moisture contents are relatively constant in the beginning, then increase up to the value corresponding to the saturated state (0.37) after a series of intensive rainfall events. Afterward, the values decrease down to the minimum but with rebounds occurring in case of rainfall at the end of $2014 / 8$. The saturated values were reached again with rainfall events at the end of $2015 / 8$, and the volumetric moisture content remained almost constant at the saturated value after 2016/1. Furthermore, compared with point A2, point A3 is nearer the embankment surface and thus influenced by both the top and slope boundary conditions. Thereby, the volumetric moisture content at point A1 has larger value variation amplitude, suggesting a higher sensitivity to infiltration/ evaporation. For the calculations, they go up till they nearly reach the saturated value in $2015 / 7$. Going through several variations in the spring/summer, they finally increase again to reach the saturated value in 2016/7. In particular, due to the closest distance to the slope boundary among the three points, point A1 shows more significant changes than the two others.

4.3. Flow and Volumetric Water Storage Variations. The situation of the flow and volumetric water storage (VWS) through three faces and the volumetric water storage of the new embankment is presented in Figure 10. On the slope, rainfall infiltration and evaporation occurred with the change of climate environment. From 2013/7 to 2015/3, the main performance is the evaporation, which showed that the evaporation was greater than the infiltration with the largest difference, and the volumetric water storage is negative and is a curve that decreases with time and the minimum value is $-3.12 \mathrm{~m}^{3}$. After 2015/3, rainfall infiltration mainly occurred from May to August, and evaporation mainly concentrated from September to April. The amount of infiltration exceeded the amount of evaporation, and the curve of volumetric water storage for slope rose. For the foundation 


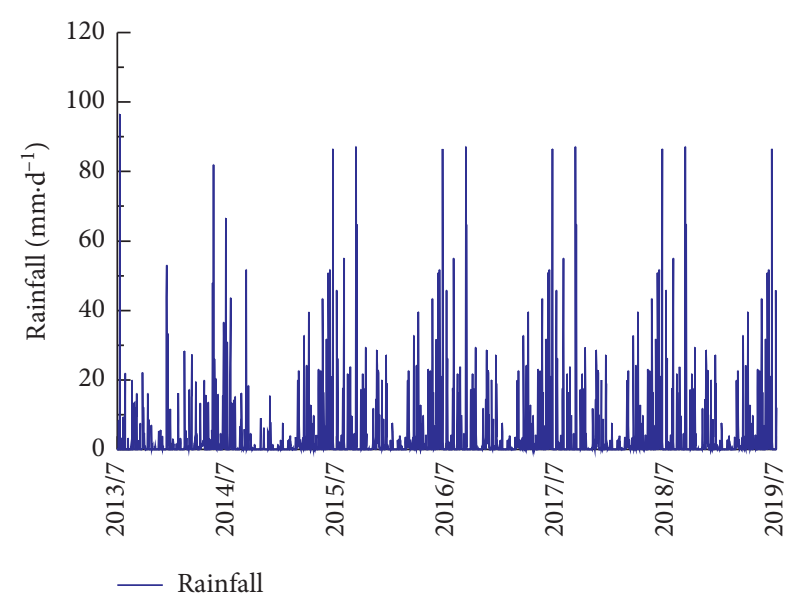

(a)

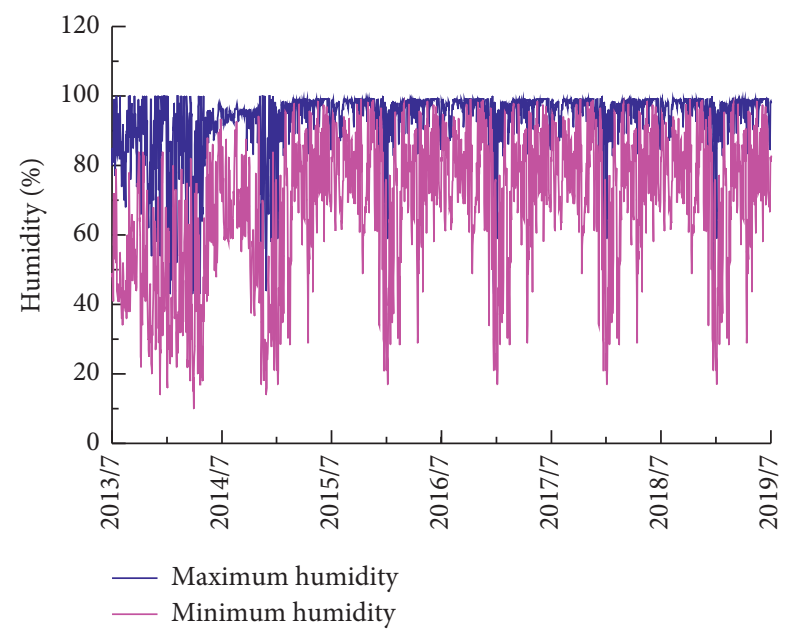

(c)

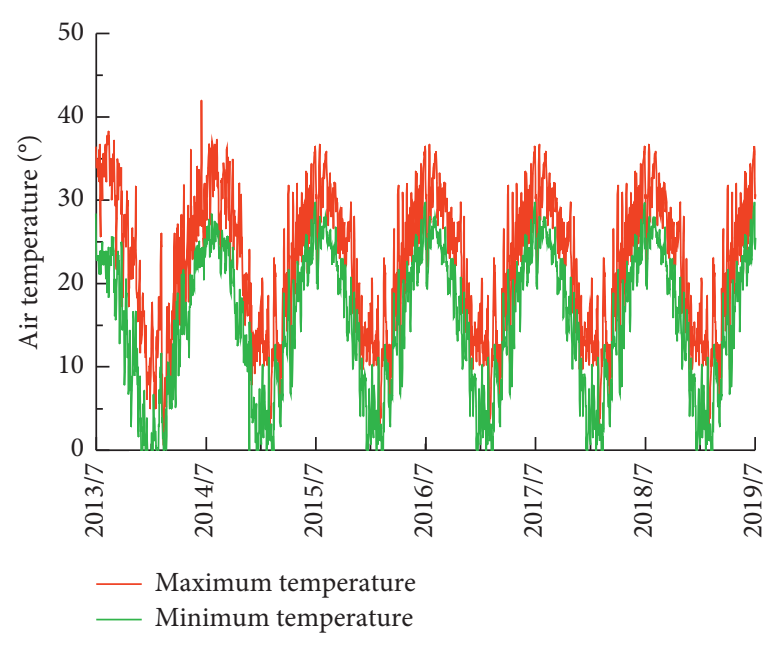

(b)

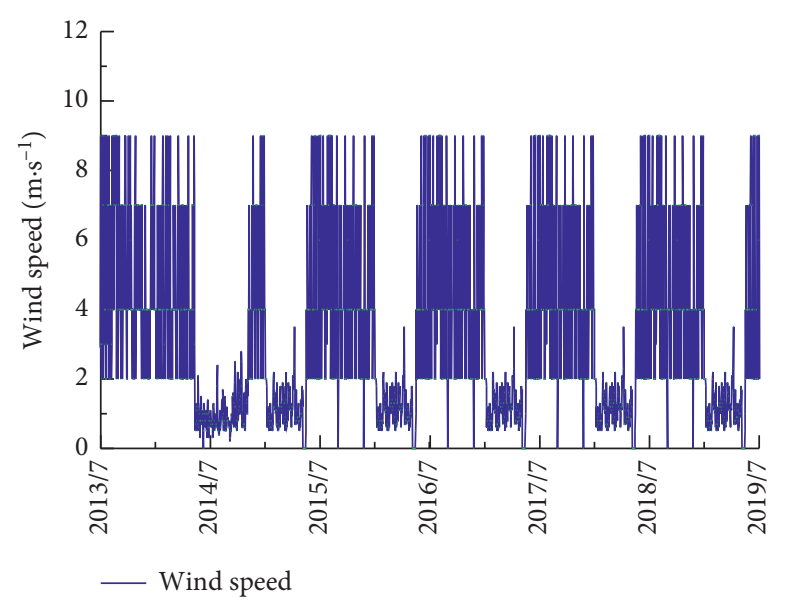

(d)

Figure 6: Field meteorological data: (a) rainfall; (b) temperature; (c) relative humidity; (d) wind speed [23].

TABLE 2: Numerical program of sand cushion without and with atmospheric environment.

\begin{tabular}{lccc}
\hline Studied cases & Cover $(\mathrm{CO})$ & Cushion $(\mathrm{CU})$ & Partition $(\mathrm{PA})$ \\
\hline Case 0 & - & - & - \\
Case 1 & $\sqrt{ }$ & - & - \\
Case 2 & - & $\sqrt{ }$ & - \\
Case 3 & - & - & $\sqrt{ }$ \\
Case 4 & $\sqrt{ }$ & - & - \\
Case 5 & $\sqrt{ }$ & $\sqrt{ }$ & $\sqrt{ }$ \\
Case 6 & - & $\sqrt{ }$ & $\sqrt{ }$ \\
Case 7 & $\sqrt{ }$ & &
\end{tabular}

face of the new embankment, the flow through the slope fluctuates drastically and is consistent with the climatic environment. During the period from 2013/7 to $2015 / 3$, the water through the foundation surface mainly flows from the foundation to the new embankment, and the maximum flow and volumetric water storage are $0.21 \mathrm{~m}^{3} \cdot \mathrm{d}^{-1}, 1.837 \mathrm{~m}^{3}$, respectively. After 2015/3, the moisture migration changed from top to bottom. The volumetric water storage decreased and fell to zero on $2016 / 7$ and then continued to decline. Similarly, for the interface, from $2013 / 7$ to $2015 / 6$, the water flows from the existing embankment to the new embankment, and the maximum flow and volumetric water storage are $0.05 \mathrm{~m}^{3} \cdot \mathrm{d}^{-1}, 3.297 \mathrm{~m}^{3}$, respectively. After $2015 / 6$, the water begins to flow from the new embankment to the existing embankment. The volumetric water storage decreased and is close to zero on 2019/7.

Because of $2013 / 7$, in the case of just completed construction, the volumetric moisture content of the new embankment is lower and the matrix suction is larger. From $2013 / 7$ to $2014 / 3$, the lower permeability coefficient makes the rainwater more difficult to infiltrate, and the water evaporation is relatively large due to the high temperature. Although, from 2014/4 to 2014/8, it is clear from the increase in the total water volume curve that the infiltration amount exceeds the evaporation amount, the evaporation from 2014/ 8 to $2015 / 3$ is still stronger than the infiltration. At this time, the soil of the new embankment is widely absorbed from the foundation and the interface because the volumetric moisture content of the foundation and the existing 


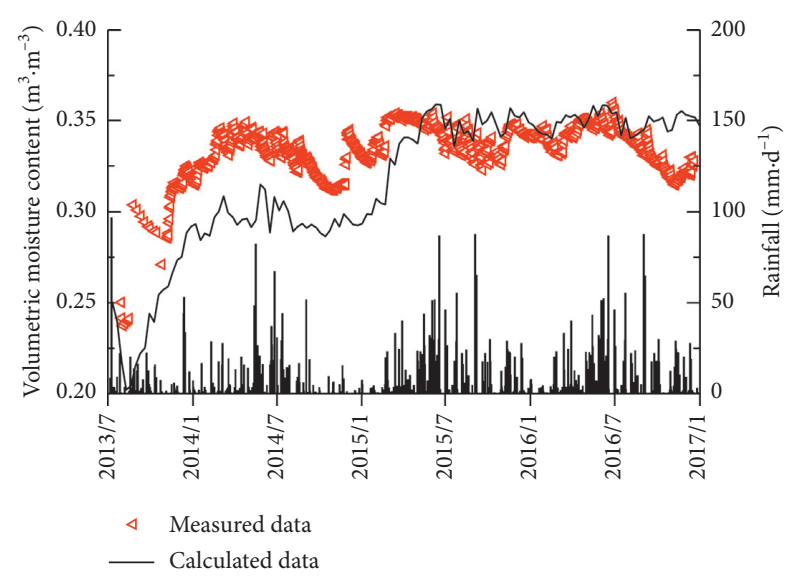

(a)

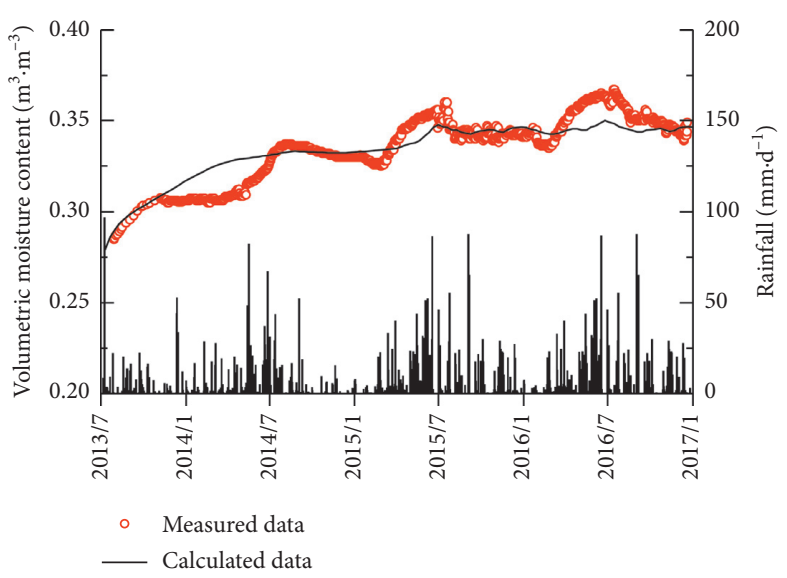

(b)

Figure 7: Comparison between measured and calculated volumetric moisture contents: (a) the location of sensor \#6; (b) the location of sensor \#4 [23].

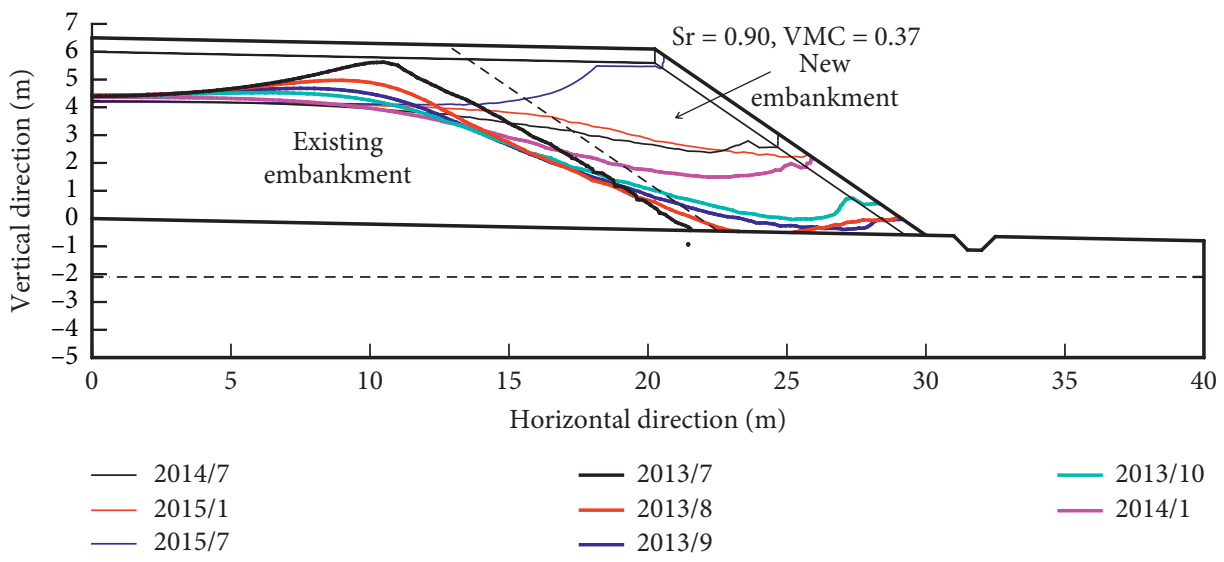

(a)

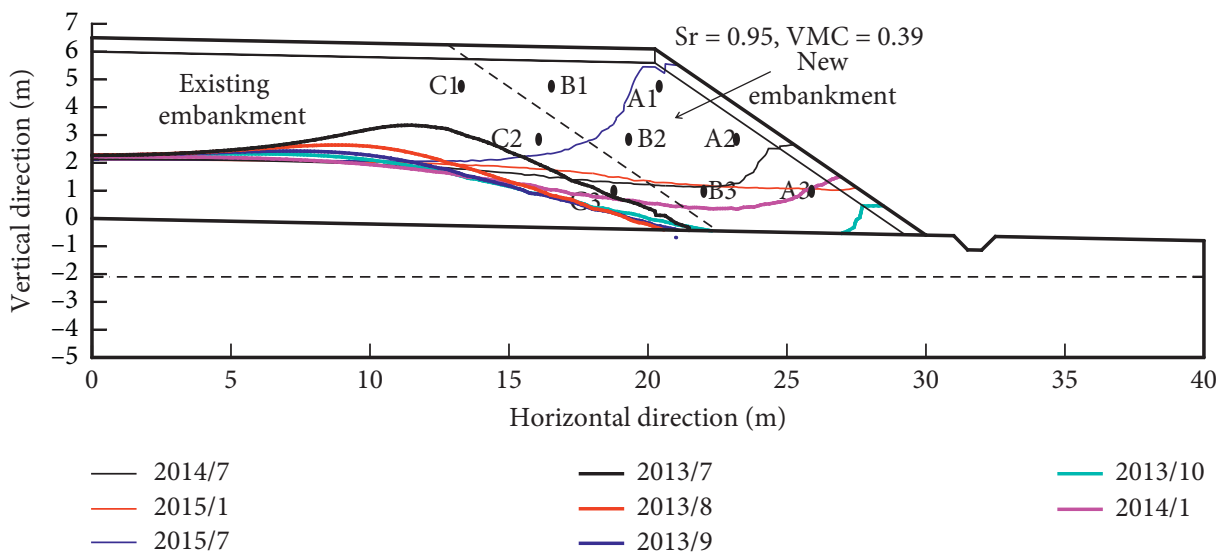

(b)

FIGURE 8: Volumetric moisture content contour over time: (a) VMC $=0.37$ and (b) VMC $=0.39$.

embankment is higher than that of the new one, and the amount through the interface is greater than that from the foundation because the length of the interface is longer and the moisture migration does not need to overcome the gravity effect. However, after that, the amount of evaporation is consistently smaller than the amount of infiltration, and the water in the soil continues to increase. As a result, the soil in the surface layer of the slope is high and gradually 

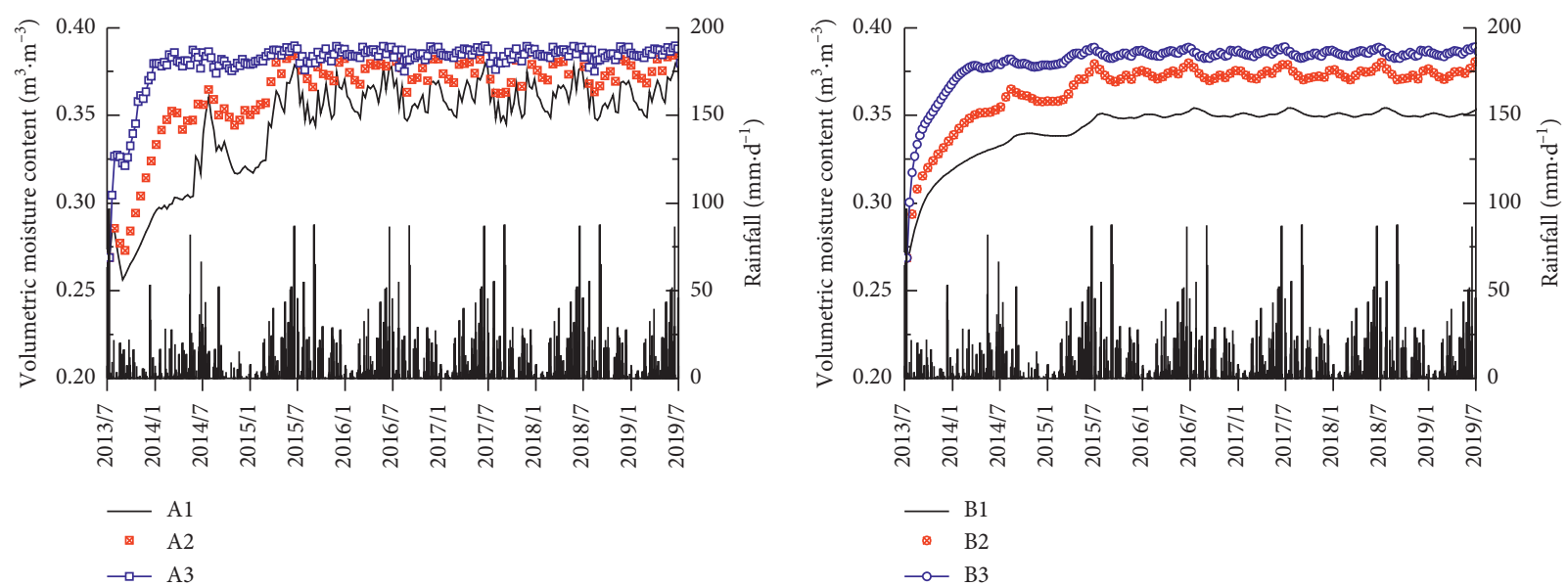

(a)

(b)

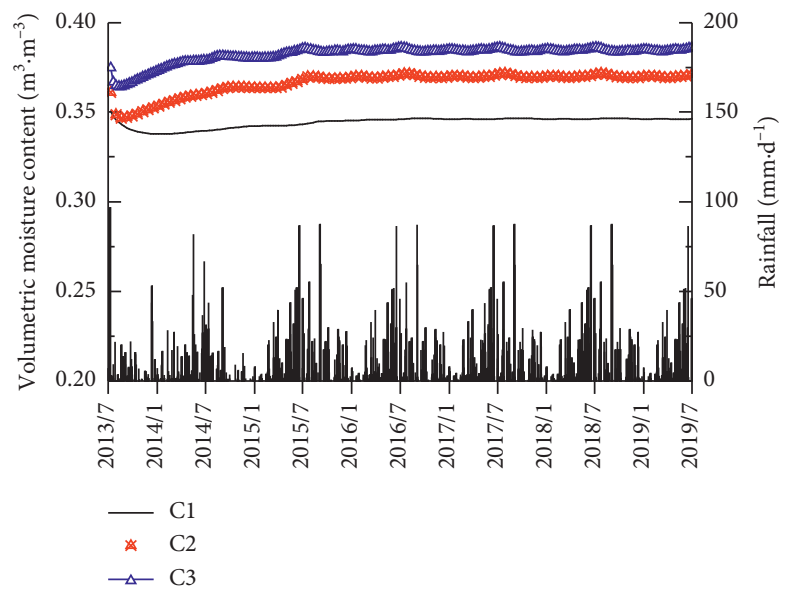

(c)

FIGURE 9: Volumetric moisture content overtime of 9 points: (a) A1 A3; (b) B1 B3; (c) C1 C3.

migrates into the interior of the embankment. In addition, due to gravity, the water is more likely to flow through the foundation surface to the foundation. According to the above analysis, the internal volumetric moisture content of the new embankment will gradually increase from the completion of the construction. Early in the first 1 2 years, the water mainly comes from the foundation and the existing embankment. After that, as time goes by, the water mainly comes from the slope infiltration and gradually migrates to the foundation and the existing embankment, and the volumetric water storage gradually reaches equilibrium.

\subsection{Influence of Capillary Barrier on the Volumetric Moisture} Content Distribution. Numerical simulations for the 7 combinations of the cushion, the cover, and the partition using a capillary barrier by sand were performed. To compare the difference in volumetric water storage and volumetric moisture content using the capillary barrier, cross-section S1, point A1, and point B3 were selected.

Figure 11 shows that the volumetric water storage using the capillary barrier is significantly different from that of the new embankment. From Figure 11(a), the volumetric water storage in case 1 to case 3 is significantly improved to $2.25 \mathrm{~m}^{3}$, and after $2016 / 7$, the volumetric water storage range is between $2.0 \mathrm{~m}^{3}$ and $2.4 \mathrm{~m}^{3}$. The amplitude of volumetric water storage variation of the cushion or the partition using the capillary barrier is basically the same as the new embankment, and the cover using the capillary barrier is free of fluctuations because it blocks the climatic environment. Likewise, the volumetric water storage of case 4 to case 6 is significantly improved to $2.25 \mathrm{~m}^{3}$, and after $2017 / 7$, the volumetric water storage range of the cushion and the partition using capillary barrier is between $2.0 \mathrm{~m}^{3}$ and $2.4 \mathrm{~m}^{3}$ and that of the other is $2.25 \mathrm{~m}^{3}$, as shown in Figure 11(b). In case 7 , when the three are used together, the volumetric water storage is basically zero.

Similarly, the volumetric moisture contents using the capillary barrier at point $\mathrm{A} 1$ and point $\mathrm{B} 3$, as shown in Figure 12, are significantly different from that without the capillary barrier. Except case 7, the volumetric moisture contents of case 1 to case 6 are significantly improved from the initial 0.27 to 0.36 , and the volumetric moisture content of long period fluctuation range is between 0.35 and 0.38 after $2014 / 7$ or $2015 / 7$, and the equilibrium volumetric moisture content of points A1 and B3 is 0.36 and 0.38 , 

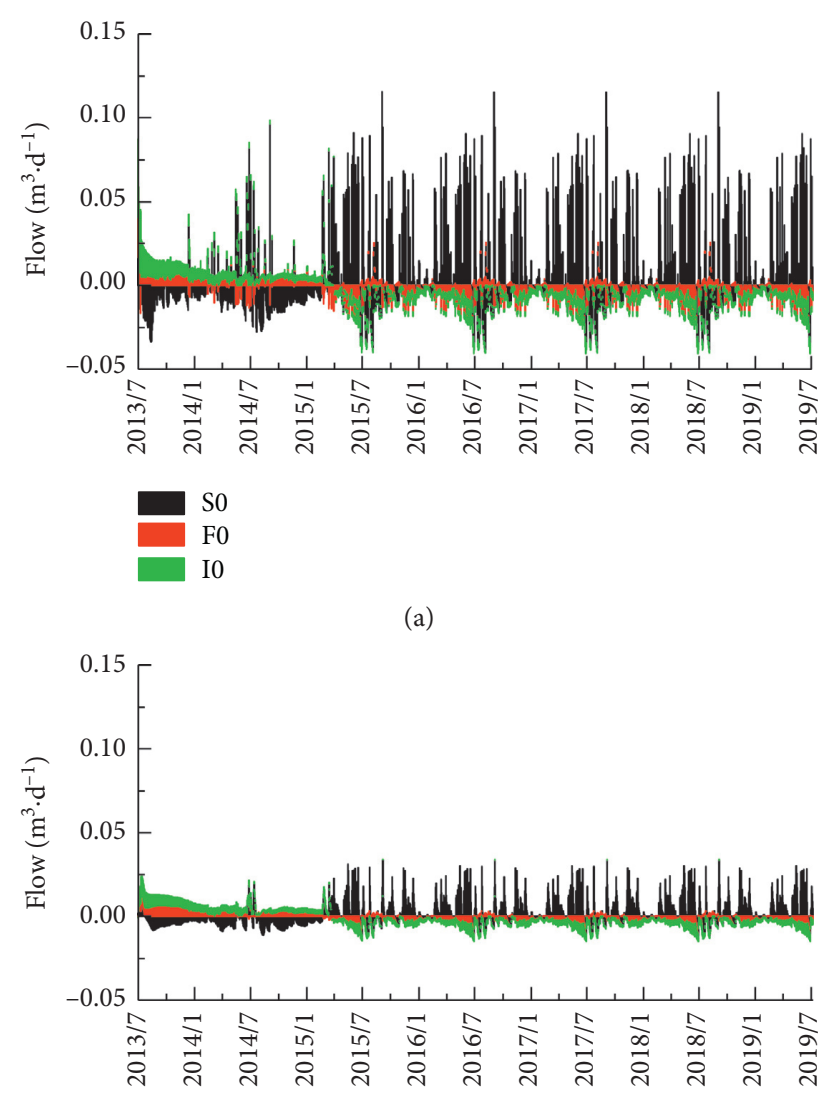

S1
F1
I1

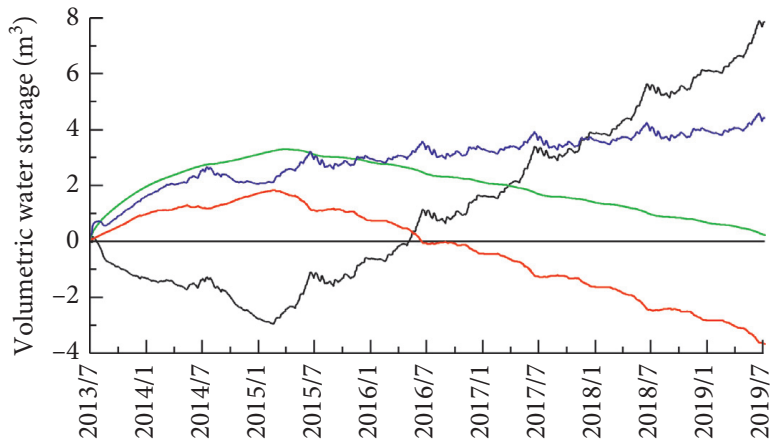

- So

- F0

I0
- VWSO

(b)

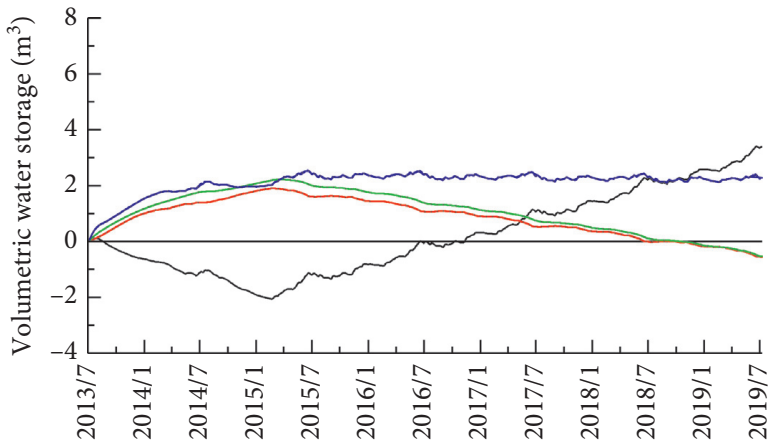

$\mathrm{S} 1$
$-\mathrm{F} 1$

- I1

(d)

Figure 10: Calculated flow and volumetric water storage over time: (a) flow of cross-sections S0, F0, I0; (b) volumetric water storage of cross-sections S0, F0, I0, and S0 + F0 + I0; (c) flow of cross-sections S1, F1, I1; (d) volumetric water storage of cross-sections S1, F1, I1 and $\mathrm{S} 1+\mathrm{F} 1+\mathrm{I} 1$

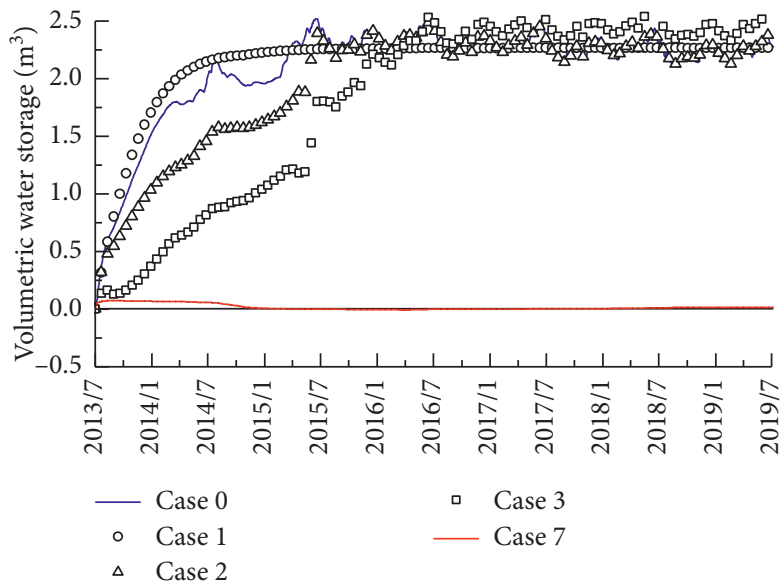

(a)

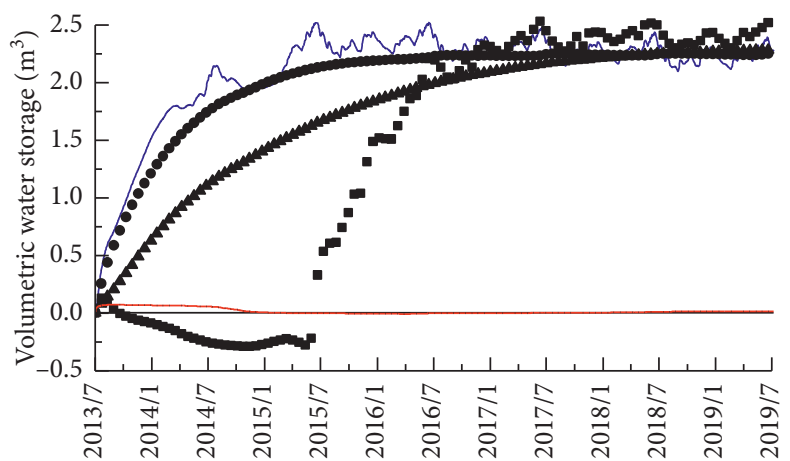

- Case 0

- Case 6

- Case 7

(b)

Figure 11: Comparison of volumetric water storage for a different combination: (a) cases 0, 1, 2, 3, and 7; (b) cases $0,4,5,6$, and 7. 


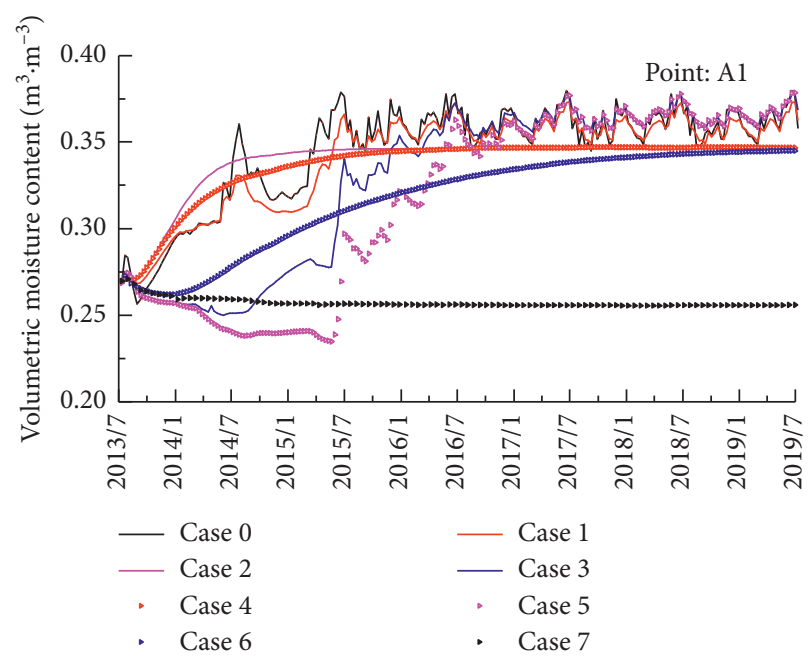

(a)

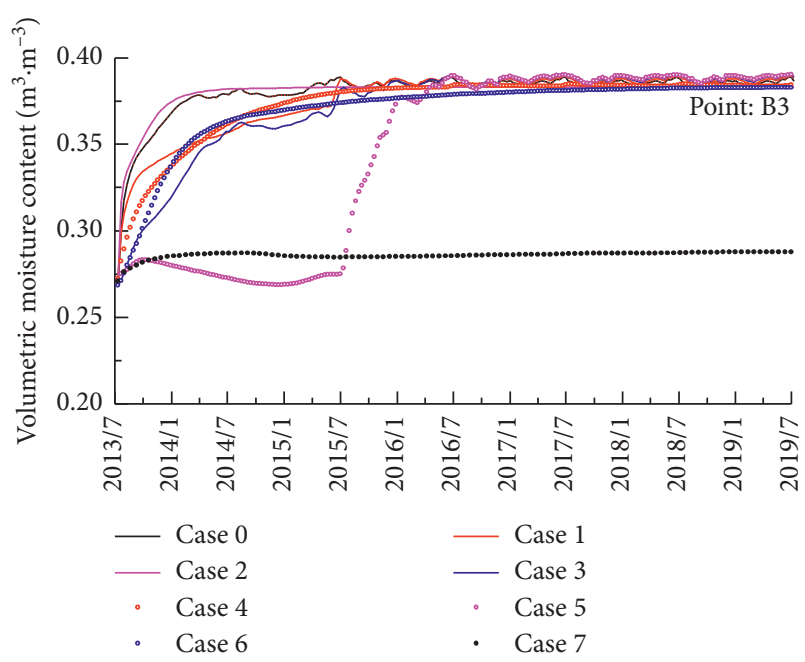

(b)

Figure 12: Comparison of the volumetric moisture content for the different combination: (a) point A1 and (b) point B3.

respectively. In case 7 , the volumetric moisture content is basically near the initial moisture content, and due to gravity, the equilibrium volumetric moisture content of points A1 and B3 is 0.26 and 0.28 .

Whether one or two of the cushion, the cover, and the partition using the capillary barrier are selected, the volumetric moisture content gradually increases, and finally, the volumetric moisture content change tendency of the original embankment is consistent. Only when the cushion, the cover, and the partition are used together with the capillary barrier, the volumetric moisture content will not increase, basically a horizontal line. Because when one or two are selected for using capillary barrier, the new embankment retains the passage of water from the outside to the inside. Therefore, the increases in moisture content and the equilibrium moisture content in the embankment are basically the same as the originally embankment. However, when the three are used, all boundaries of the new embankment are blocked, and the water cannot enter the interior of the new embankment, so the volumetric moisture content remains unchanged.

\section{Influence of Capillary Barrier on the Resilient Modulus and Factor of Safety}

Based on the volumetric moisture content in exponential forms to reflect the relationship between the volumetric moisture content and resilient modulus, many prediction models of the resilient modulus can be established. Numerous experimental studies of the previous researchers have demonstrated that the volumetric moisture content is negatively related to the resilient modulus. Considering the influence of matric suction and stress state on the resilient modulus, Zhang et al. [33,34] proposed a prediction model.

$$
M_{R}=k_{0} P_{a} \mathrm{RC}^{k_{1}}\left(\frac{\psi}{P_{a}}+1\right)^{k_{2}}\left(\frac{\theta_{m}}{P_{a}}\right)^{k_{3}}\left(\frac{\tau_{\mathrm{oct}}}{P_{a}}+1\right)^{k_{4}},
$$

where $M_{R}$ is the resilient modulus; $P_{a}$ is the atmospheric pressure, and $P_{a}=101.3 \mathrm{kPa}$, RC is the relative compaction, defined as the ratio of dry density to maximum dry density; $\psi$ is the matric suction; $\theta_{m}$ is the minimum bulk stress under certain stress conditions; $\tau_{\text {oct }}$ is the octahedral shear stress; $k_{0}, k_{1}, k_{2}, k_{3}$, and $k_{4}$ are the regression coefficients.

When the resilient modulus was calculated, various stresses (e.g., $\sigma_{1}$ and $\sigma_{3}$ ) can be calculated, and the suction of the corresponding point was obtained. Then, the values of $\theta_{m}, \tau_{\text {oct }}, k_{0}, k_{1}, k_{2}, k_{3}$, and $k_{4}$ were calculated. At last, the resilient modulus of the soil at point A1 of the embankment was calculated, as shown in Figure 13(a). The resilient modulus of the eight cases is different due to volumetric moisture content-dependency. The resilient modulus decreases from $99 \mathrm{MPa}$ down to $40 \mathrm{MPa}$ of case 0 to case 6 , and the resilient modulus is $60 \%$, and their resilient modulus curves are different because it corresponds to the increase in volumetric moisture content. And the resilient modulus and volumetric moisture content of case 7 are $102 \mathrm{MPa}, 0.25$, respectively, which are the same as the initial state. The faster the volumetric moisture content increases, the greater the resilient modulus decreases. Therefore, it is important to keep the matric suction stability for the new embankment.

Similarly, the factors of safety will change because the strength parameters of the embankment soil change with the fluctuation of volumetric moisture content, and many methods [35-37] can be used to solve it. In this study, the factors of safety using the Bishop method [38] for the most dangerous slip surface by the SLOPE/W module are shown in Figure 13(b). It is noted that the factors of safety fluctuate with the variation in the volumetric moisture content and they change from 4.5 to 2.0 of the case 0 to case 6 , and the most dangerous slip surface passes through the bottom of the slope. The factor of safety value of case 7 is 4.5 . Therefore, it is essential to keep the volumetric moisture content for the new embankment to avoid slope collapses.

The cushion, the cover, and the partition are used together with the capillary barrier because the capillary barrier 


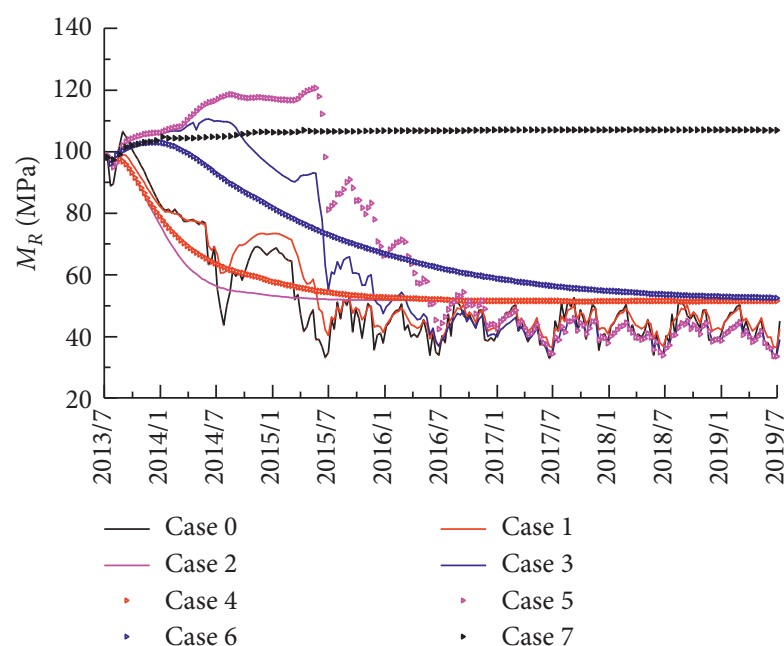

(a)

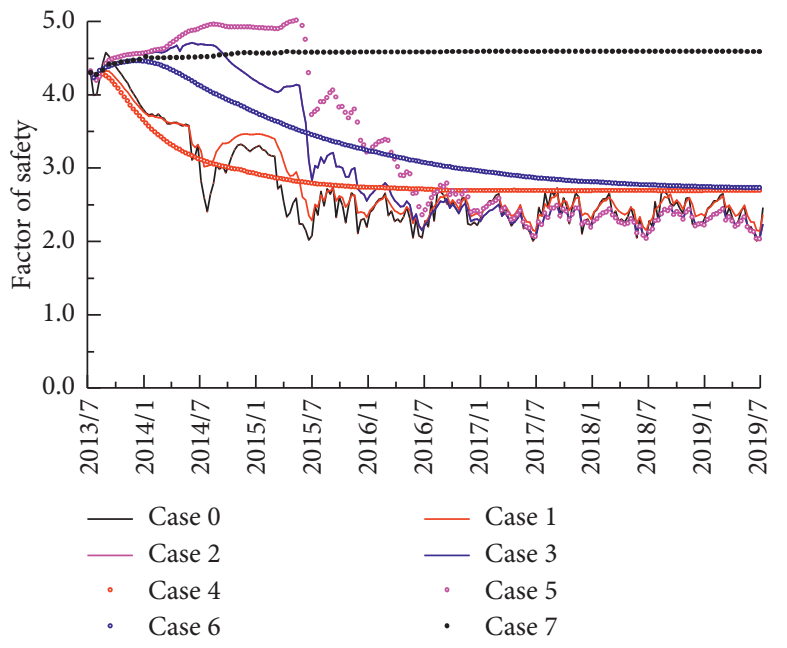

(b)

FIGURE 13: Variation of resilient modulus and factor of safety over time: (a) resilient modulus; (b) factor of safety.

blocks the rise of groundwater capillary, rainwater infiltration, and water migration from the existing embankment. Thereby, the resilient modulus, permanent deformation, shear strength, and expansion force associated with humidity or matric suction inside the embankment will not change greatly. In summary, the new embankment with the cushion, cover, and partition using capillary barrier is a durable design.

\section{Conclusions}

In order to reveal the moisture migration of the new embankment under the existing embankment, groundwater, and climate environment and obtain a method to control the change of moisture content of the new embankment in southern China, six FDR sensors were installed to monitor the volumetric moisture content in the existing and new embankment of the Chang-Zhang expressway. The finite element model of the embankment was developed and verified. Seven combined calculations of the cushion, the cover, and the partition using the capillary barrier were carried out. The main findings of this study were summarized as follows.

(1) The good agreement between calculated and measured volumetric moisture contents verifies the rationality of the numerical simulation. It also ensures that the adopted soil parameters are appropriate.

(2) Early in the first 1 2 years, the water mainly comes from the foundation and the existing embankment. After that, as time goes by, the water mainly comes from the rainwater infiltration and gradually migrates to the foundation and the existing embankment, and the volumetric water storage gradually reaches equilibrium.

(3) The combination of the cushion, cover, and partition using capillary barrier is a very effective method to control the stability of the volumetric moisture content in the new embankment in southern China. This combination blocks the rise of groundwater capillary, rainwater infiltration, and water migration from the existing embankment. The equilibrium moisture content in the new embankment is basically consistent with OMC, and the increase of flow and volumetric water storage is basically zero.

(4) The influence of capillary barrier on the resilient modulus and factor of safety used was calculated. The resilient modulus and factor of safety used together with the cover, cushion, and partition are the same as those during construction. Those of the other combinations are reduced by $40 \%$ to $60 \%$.

\section{Data Availability}

The data used to support the findings of this study are available from the corresponding author upon request.

\section{Conflicts of Interest}

The authors declare that there are no conflicts of interest regarding the publication of this paper.

\section{Acknowledgments}

The authors gratefully acknowledge the financial support offered by the National Key Research and Development Program of China (2017YFC0805307), the National Natural Science Foundation of China (51838001, 51878070, 51878078, 51911530215, and 51927814), the Excellent Youth Foundation of Natural Science Foundation of Hunan Province (2018JJ1026), and the Key Project of Education Department of Hunan Province (17A008). This work was also supported by the Key Project of Open Research Fund of National Engineering Laboratory of Highway Maintenance Technology (kfj150103 and kfj170501), the Training Program for High-level Technical Personnel in Transportation Industry (2018-025), and the Hunan Provincial Innovation Foundation for Postgraduate (CX2018B527). 


\section{References}

[1] K. Hatami, D. Esmaili, E. C. Chan, and G. A. Miller, "Laboratory performance of reduced-scale reinforced embankments at different moisture contents," International Journal of Geotechnical Engineering, vol. 8, no. 3, pp. 260-276, 2014.

[2] J. Zhang, L. Ding, F. Li, and J. Peng, "Recycled aggregates from construction and demolition wastes as alternative filling materials for highway subgrades in China," Journal of Cleaner Production, vol. 255, Article ID 120223, 2020.

[3] K.-H. Yang, J. N. a. a. Thuo, V. D. A. Huynh, T. S. Nguyen, and F. H. M. Portelinha, "Numerical evaluation of reinforced slopes with various backfill-reinforcement-drainage systems subject to rainfall infiltration," Computers and Geotechnics, vol. 96, pp. 25-39, 2018.

[4] F. Vahedifard, K. Mortezaei, B. A. Leshchinsky, D. Leshchinsky, and N. Lu, "Role of suction stress on service state behavior of geosynthetic-reinforced soil structures," Transportation Geotechnics, vol. 8, pp. 45-56, 2016.

[5] L. Zeng, L.-Y. Xiao, J.-H. Zhang, and Q.-F. Gao, "Effect of the characteristics of surface cracks on the transient saturated zones in colluvial soil slopes during rainfall," Bulletin of Engineering Geology and the Environment, vol. 79, no. 2, pp. 699-709, 2019.

[6] Y. Yao, J. Zheng, J. Zhang, J. Peng, and J. Li, "Model for predicting resilient modulus of unsaturated subgrade soils in south China," KSCE Journal of Civil Engineering, vol. 22, no. 6 , pp. 2089-2098, 2018.

[7] G. W. Li, A. C. Amenuvor, Y. Z. Hou, X. C. Lu, J. T. Wu, and T. N. Nguyen, "Effect of open-ended PHC pile installation during embankment widening on the surrounding soil," Journal of Geotechnical and Geoenvironmental Engineering, vol. 145, no. 2, 2019.

[8] S. M. Rao and R. Malini, "Role of degree of saturation in denitrification of unsaturated sand specimens," Environmental Earth Sciences, vol. 72, no. 11, pp. 4371-4380, 2014.

[9] L. Z. Wu, L. M. Zhang, Y. Zhou, and B. E. Li, "Analysis of multi-phase coupled seepage and stability in anisotropic slopes under rainfall condition," Environmental Earth Sciences, vol. 76, no. 14, 2017.

[10] R. Zhang, Z. Liu, J. Zheng, and J. Zhang, "Experimental evaluation of lateral swelling pressure of expansive soil fill behind a retaining wall," Journal of Materials in Civil Engineering, vol. 32, no. 2, Article ID 04019360, 2020.

[11] J. Peng, J. Zhang, J. Li, Y. Yao, and A. Zhang, "Modeling humidity and stress-dependent subgrade soils in flexible pavements," Computers and Geotechnics, vol. 120, Article ID 103413, 2020.

[12] J. Qian, Y. Yao, J. Li, H. Xiao, and S. Luo, "Resilient properties of soil-rock mixture materials: preliminary investigation of the effect of composition and structure," Materials, vol. 13, no. 7, p. $1658,2020$.

[13] K. Liu, P. J. Vardon, M. A. Hicks, and P. Arnold, "Combined effect of hysteresis and heterogeneity on the stability of an embankment under transient seepage," Engineering Geology, vol. 219, pp. 140-150, 2017.

[14] J. H. Zhang, J. H. Peng, A. S. Zhang, and J. Li, "Prediction of permanent deformation for subgrade soils under traffic loading in southern China," International Journal of Pavement Engineering, pp. 1-10, 2020.

[15] G. Tu and R. Huang, "Infiltration in two types of embankments and the effects of rainfall time on the stability of slopes," Quarterly Journal of Engineering Geology and Hydrogeology, vol. 49, no. 4, pp. 286-297, 2016.
[16] R. K. Rowe, R. W. I. Brachman, W. A. Take, A. Rentz, and L. E. Ashe, "Field and laboratory observations of down-slope bentonite migration in exposed composite liners," Geotextiles and Geomembranes, vol. 44, no. 5, pp. 686-706, 2016.

[17] L. Jie, H. Yao, P. Chen, Z. Lu, and X. Luo, “Theoretical analysis and experimental study of subgrade moisture variation and underground antidrainage technique under groundwater fluctuations," Journal of Applied Mathematics, vol. 2013, Article ID 703251, 8 pages, 2013.

[18] N. An, S. Hemmati, and Y. Cui, "Numerical analysis of soil volumetric water content and temperature variations in an embankment due to soil-atmosphere interaction," Computers and Geotechnics, vol. 83, pp. 40-51, 2017.

[19] A. S. Lees, G. J. MacDonald, A. Sheerman-Chase, and F. Schmidt, "Seasonal slope movements in an old clay fill embankment dam," Canadian Geotechnical Journal, vol. 50, no. 5, pp. 503-520, 2013.

[20] Y. Tao, S. Wang, D. Xu, H. Yuan, and H. Chen, "Field and numerical experiment of an improved subsurface drainage system in Huaibei plain," Agricultural Water Management, vol. 194, pp. 24-32, 2017.

[21] Z. Wang, Y. Xie, J. Qiu, Y. Zhang, and H. Fan, "Field experiment on soaking characteristics of collapsible loess," Advances in Materials Science and Engineering, vol. 2017, Article ID 6213871, 17 pages, 2017.

[22] K. Hatami, D. Esmaili, E. C. Chan, and G. A. Miller, "Moisture reduction factors for shear strength of unsaturated reinforced embankments," Interantional Journal of Geomechanics, vol. 16, no. 6, 2016.

[23] Y.-S. Yao, J.-L. Zheng, Z.-S. Chen, J.-H. Zhang, and Y. Li, "Field measurements and numerical simulations of temperature and moisture in highway engineering using a frequency domain reflectometry sensor," Sensors, vol. 16, no. 6, p. 857, 2016.

[24] R. V. Nicholson, R. W. Gillham, J. A. Cherry, and E. J. Reardon, "Reduction of acid generation in mine tailings through the use of moisture-retaining cover layers as oxygen barriers: reply," Canadian Geotechnical Journal, vol. 27, no. 3, pp. 402-403, 1990.

[25] G. W. Gee, A. L. Ward, and P. D. Meyer, "Method to estimate water storage capacity of capillary barriers," Journal of Geotechnical \& Geoenvironmental Engineering, vol. 125, no. 10, pp. 297-302, 1998.

[26] S. Nirjhar, N. Mahmood, and R. Mark, "Extinction depth and evapotranspiration from ground water under selected land covers," Ground Water, vol. 45, no. 3, pp. 329-338, 2007.

[27] D. Cao, H. Fang, F. Wang, H. Zhu, and M. Sun, "A fiber Bragg-grating-based miniature sensor for the fast detection of soil moisture profiles in highway slopes and subgrades," Sensors, vol. 18, no. 12, p. 4431, 2018.

[28] O. Abuhajar, H. El Naggar, and T. Newson, "Numerical modeling of soil and surface foundation pressure effects on buried box culvert behavior," Journal of Geotechnical and Geoenvironmental Engineering, vol. 142, no. 12, Article ID 04016072, 2016.

[29] J. D. Coleman and K. Russam, "The effect of climatic factors on subgrade moisture conditions," Geotechnique, vol. 11, no. 1, pp. 22-28, 1961.

[30] F. R. Harnas, H. Rahardjo, E. C. Leong, and J. Y. Wang, "Experimental study on dual capillary barrier using recycled asphalt pavement materials," Canadian Geotechnical Journal, vol. 51, no. 10, pp. 1165-1177, 2014.

[31] H. Yang, H. Rahardjo, E. C. Leong, and D. G. Fredlund, "A study of infiltration on three sand capillary barriers," Canadian Geotechnical Journal, vol. 41, no. 4, pp. 629-643, 2004. 
[32] W. Zhang, C. Sun, and Q. Qiu, "Characterizing of a capillary barrier evapotranspirative cover under high precipitation conditions," Environmental Earth Sciences, vol. 75, no. 6, p. 513, 2016.

[33] J. Zhang, J. Peng, W. Liu, and W. Lu, "Predicting resilient modulus of fine-grained subgrade soils considering relative compaction and matric suction," Road Materials and Pavement Design, pp. 1-13, 2019.

[34] J. Zhang, J. Peng, L. Zeng, J. Li, and F. Li, "Rapid estimation of resilient modulus of subgrade soils using performance-related soil properties," International Journal of Pavement Engineering, pp. 1-8, 2019.

[35] J. Ji, C. Zhang, Y. Gao, and J. Kodikara, "Reliability-based design for geotechnical engineering: an inverse FORM approach for practice," Computers and Geotechnics, vol. 111, pp. 22-29, 2019.

[36] W. Zhang, J. Ji, Y. Gao, X. Li, and C. Zhang, "Spatial variability effect of internal friction angle on the post-failure behavior of landslides using a random and non-Newtonian fluid based SPH method," Geoscience Frontiers, 2020.

[37] M. Ajdari, G. Habibagahi, and A. Ghahramani, "Predicting effective stress parameter of unsaturated soils using neural networks," Computers and Geotechnics, vol. 40, pp. 89-96, 2012.

[38] J. Ji, W. Zhang, F. Zhang, Y. Gao, and Q. Lü, "Reliability analysis on permanent displacement of earth slopes using the simplified Bishop method," Computers and Geotechnics, vol. 117, Article ID 103286, 2020. 